
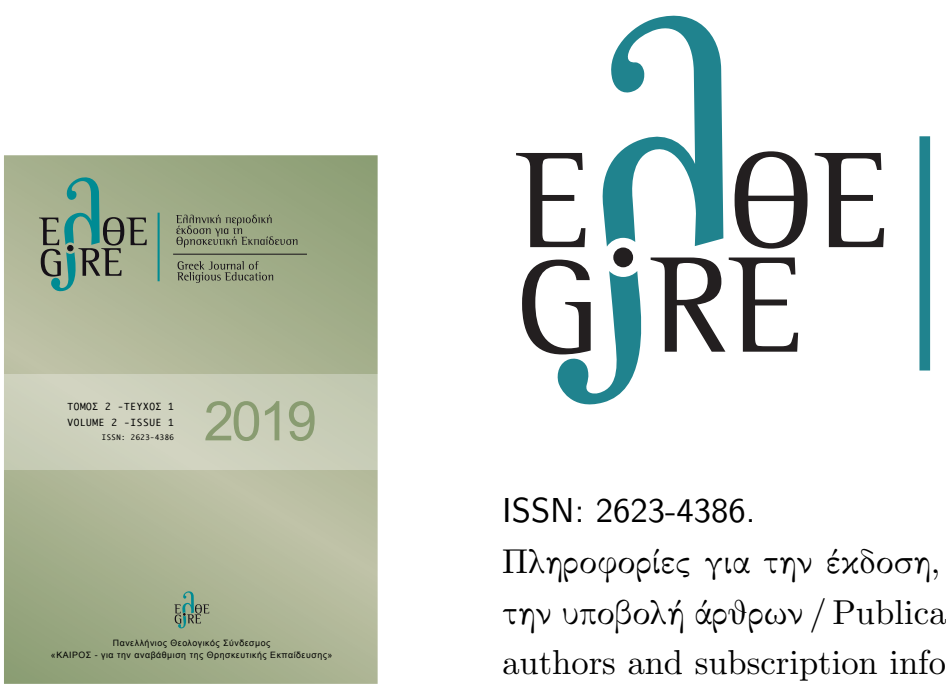

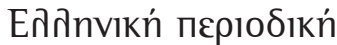

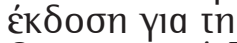

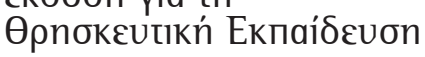

Greek Journal of

Religious Education

ISSN: 2623-4386.

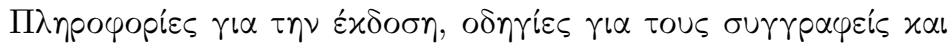

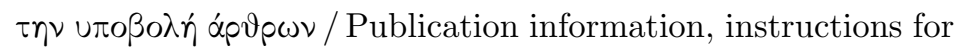
authors and subscription information: http://www.gjre.gr

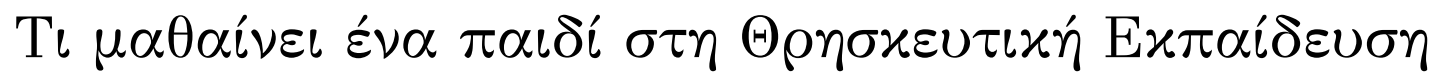 $\sigma \tau O \sigma \chi O \lambda \varepsilon i O$ \\ What does a child learn in Religious Education at school?
}

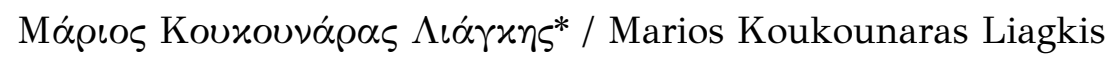

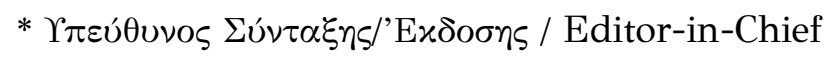

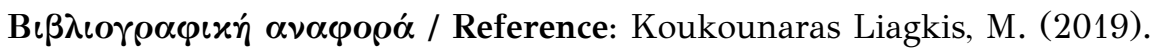

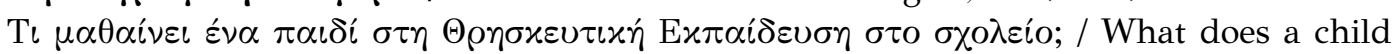

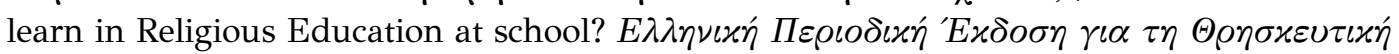
Ex $\alpha i \delta \varepsilon v \sigma \eta \eta$ / Greek Journal of Religious Education, 2(1), 9-16, DOI: 10.30457/30420191

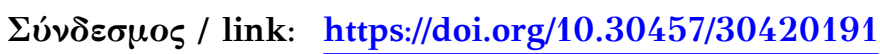

'O

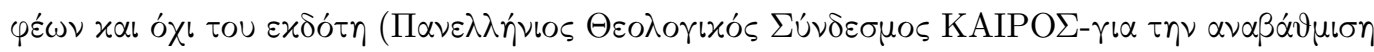

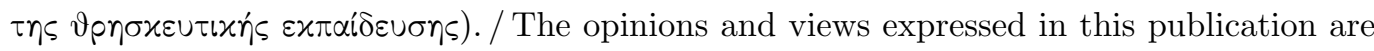
the opinions and views of the authors and not of the publisher (KAIROS - Greek Theological Association for the improvement of the Religious Education).

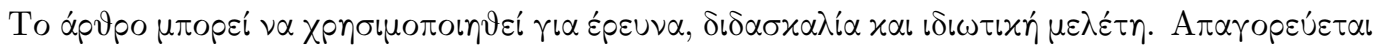

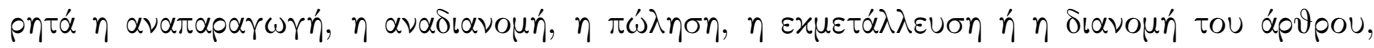

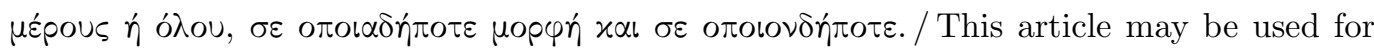
research, teaching, and private study purposes. Any substantial or systematic reproduction, redistribution, reselling, licensing or distribution in any form to anyone is forbidden.

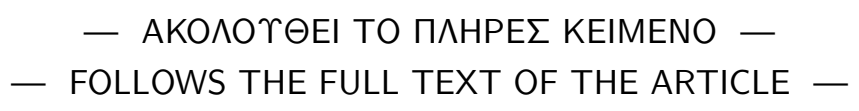




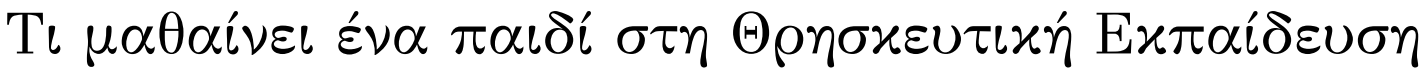

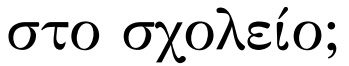

\section{What does a child learn in Religious Education at school?}

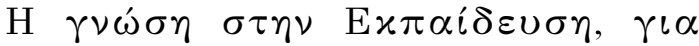
$\pi \circ \lambda \lambda o u ́ s \quad \varepsilon x \pi \alpha \iota \delta \varepsilon v \tau \iota x o u ́ \varsigma \quad x \alpha \iota$

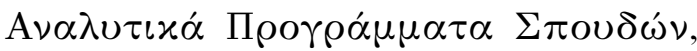
$\pi O v \varepsilon \varphi \alpha \rho \mu o ́ \zeta o \nu \tau \alpha \iota$ $\sigma \varepsilon \varepsilon x \pi \alpha \iota \delta \varepsilon v \tau \iota x \alpha ́$

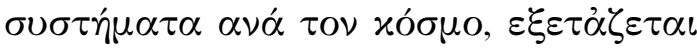

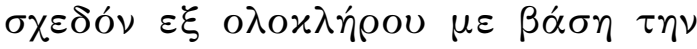

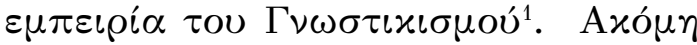

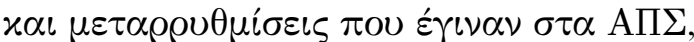

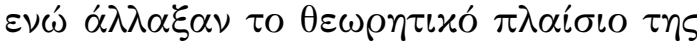

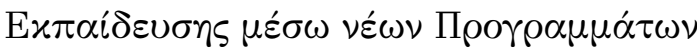
$\Sigma \pi 0 v \delta \omega \nu, \varepsilon \pi \iota \chi \varepsilon \iota \rho \omega \nu \tau \alpha \varsigma \pi \rho 0 \sigma \alpha \rho \mu о \gamma \varepsilon \dot{\varsigma} \sigma \varepsilon$

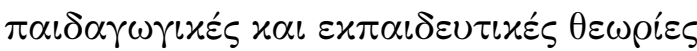

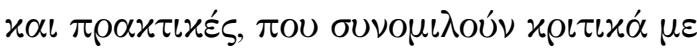

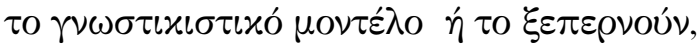

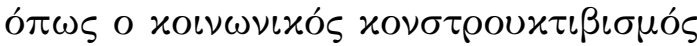

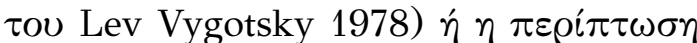

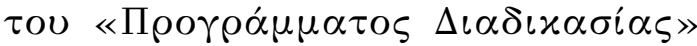

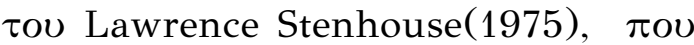

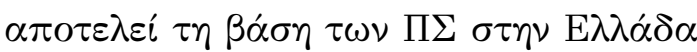

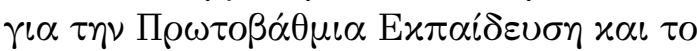

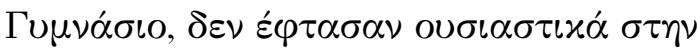

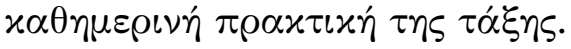

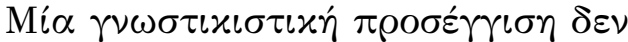

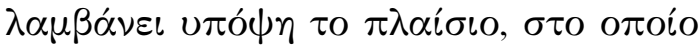

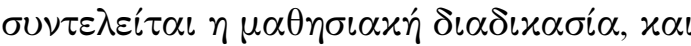

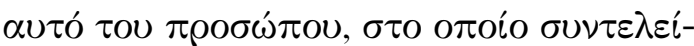

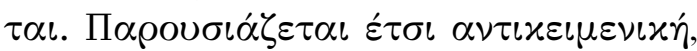
$x \alpha \theta 0 \lambda \iota x \dot{\eta} x \alpha \iota \alpha \nu \varepsilon \xi \dot{\alpha} \rho \tau \eta \tau \eta \eta$

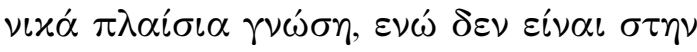

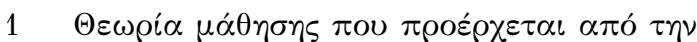

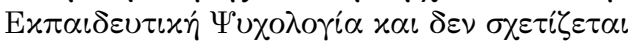

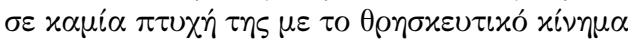
$\tau \omega \nu \pi \rho \omega \tau \tau \omega \nu ~ \chi \rho \iota \sigma \tau \iota \alpha \nu \iota x \omega \nu \nu \alpha \iota \omega \nu \omega \nu$.
Knowledge in Education, contained in Curricula and applied in educational systems around the world, is considered by many educators to be almost entirely based on the experience of Cognitivism. Even reforms made to the Curricula, which altered the theoretical framework of Education through these new curricula, and that attempted to implement adaptations to pedagogical and educational theories and practices that critically converse with or outweigh Gnosticism, such as Lev Vygotsky (1978) or the "curriculum as a process" of Lawrence Stenhouse (1975), which is the basis of the Curricula of Primary and Secondary Education (Junior High School) in Greece, did not, in reality, reach as far as daily classroom practice.

A cognitivism approach does not take into account the context in which the learning process takes place, nor consider the person to which it is applied to. It is presented as objective, universal, and space and time-independent knowledge, which in reality it is not. People and their relationships in one context cannot determine the produced knowledge. This view is based on the Vygotsky learning approach (1962) and on the role of the 


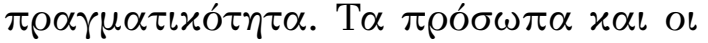

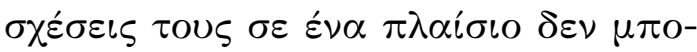

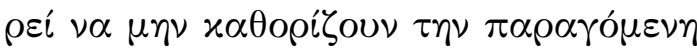

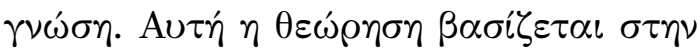

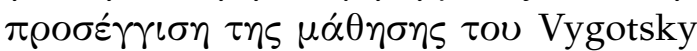

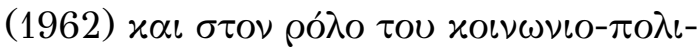

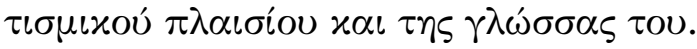

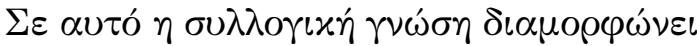

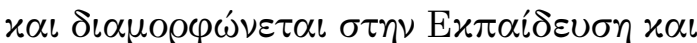

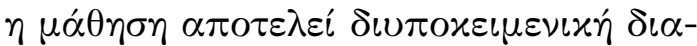

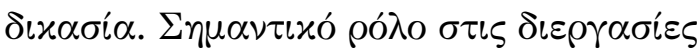

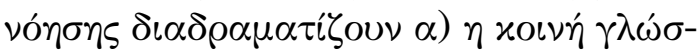

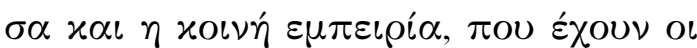

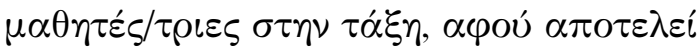

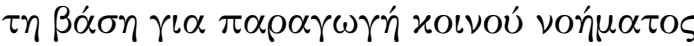

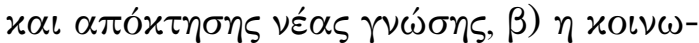

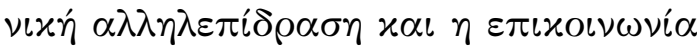

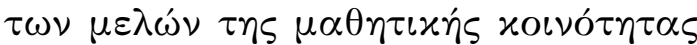

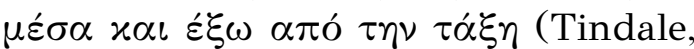
Meisenhelder, Dykema-Engblade, \& Hogg, 2016).

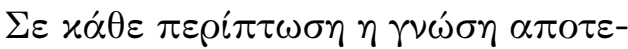

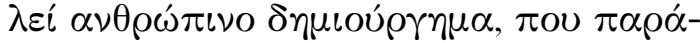

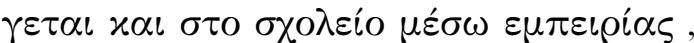

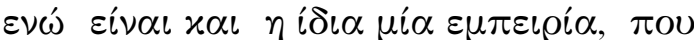

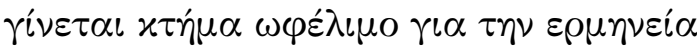

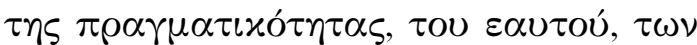

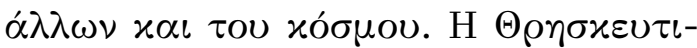

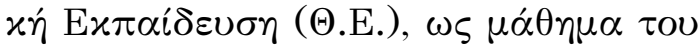

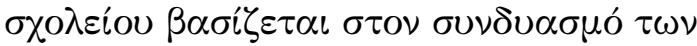

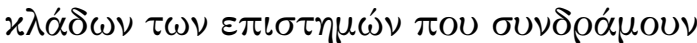

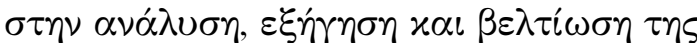

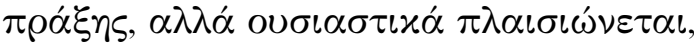
$\sigma 0 ́ \mu \varphi \omega \nu \alpha \mu \varepsilon \tau \eta \nu \varepsilon \lambda \lambda \eta \nu \iota x \eta \dot{~} \pi \rho \circ \sigma \varepsilon \dot{\gamma} \gamma\llcorner\sigma \eta$,

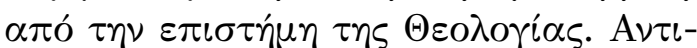

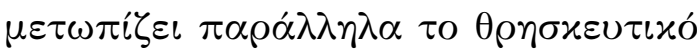

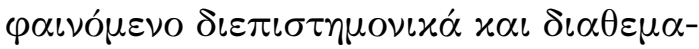

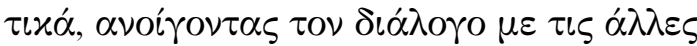

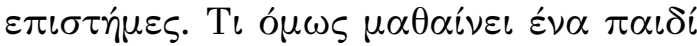

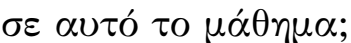

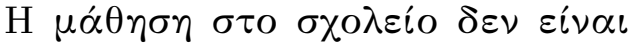

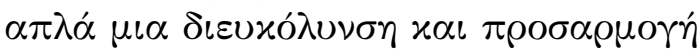

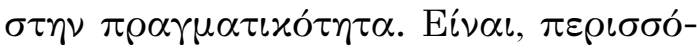

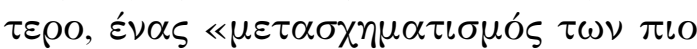

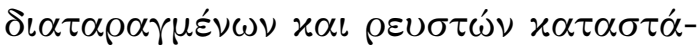

socio-cultural context and language. In this, collective knowledge shapes and is shaped in Education, and learning is an inter-subjective process. An important role played by contextualising and learning processes is a) the common language and common experience pupils have in the classroom, as they are the basis for generating common meaning and acquiring new knowledge; and $b$ ) the social interaction and communication of the student community within and outside of the classroom (Tindale, Meisenhelder, Dykema-Engblade, \& Hogg, 2016).

In any case, knowledge is a human creation. It is also produced in school through experience and it is the experience itself that is beneficial for the interpretation of reality, of the self, of others and of the world. Religious Education (R.E.), as a lesson at school is based on the combination of the disciplines of science that assist in the analysis, explanation and improvement of action, but essentially is contextualised, according to the Greek approach, by the science of Theology. At the same time, it addresses the religious phenomenon in an interdisciplinary way and cross-thematically, thereby opening the dialogue with the other sciences. But what does a child learn in this lesson?

Learning at school is not just a convenience and adaptation to reality. It is, moreover, a "transformation of the most disturbed and fluid situations into more controlled and more important" (Dewey, 


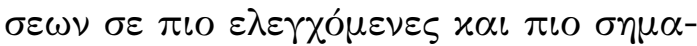

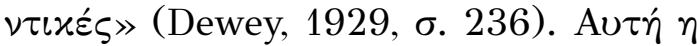

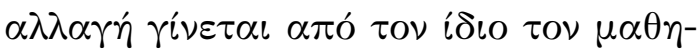

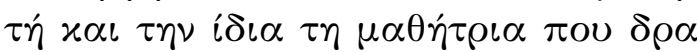

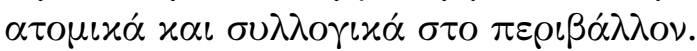

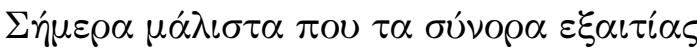

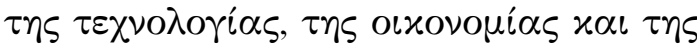

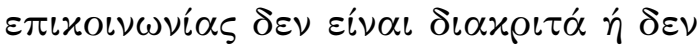

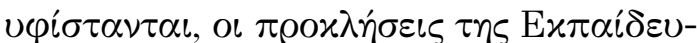

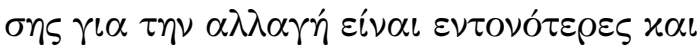

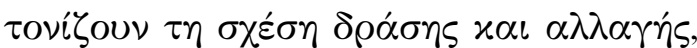

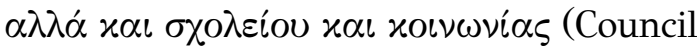

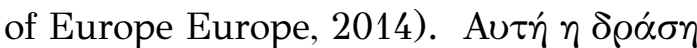

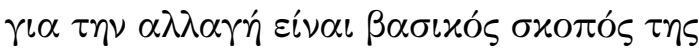

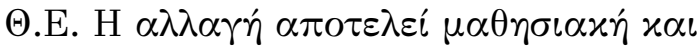

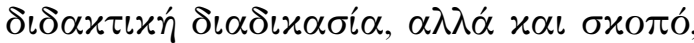
$\varepsilon \pi i \sigma \eta s$. B $\alpha \sigma \iota x \alpha ́$, o $\mu \varepsilon \tau \alpha \sigma \chi \eta \mu \alpha \tau \iota \sigma \mu o ́ s \tau \omega \nu$

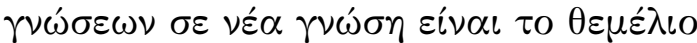

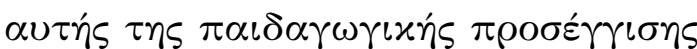

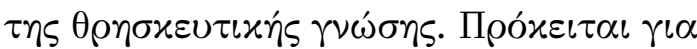

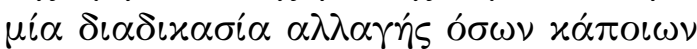

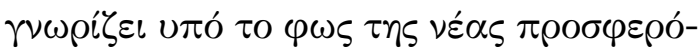

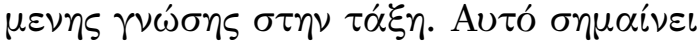

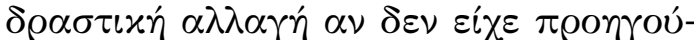

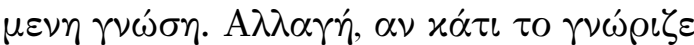

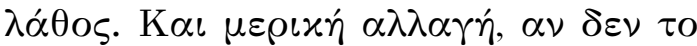

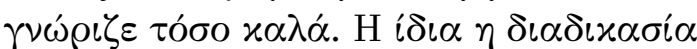

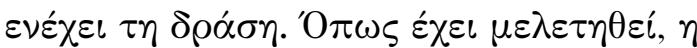

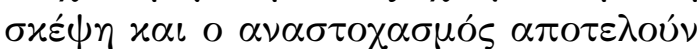

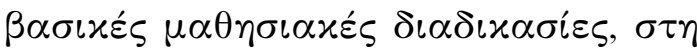

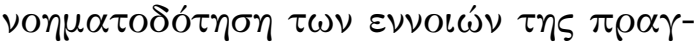

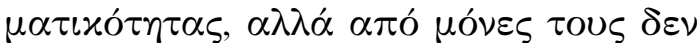

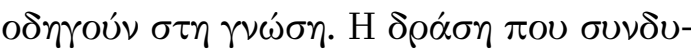

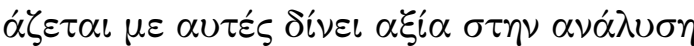

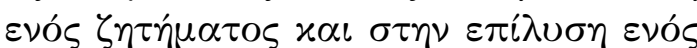

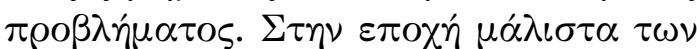
$\rho \alpha \gamma \delta \alpha i \omega \nu \alpha \lambda \lambda \alpha \gamma \omega \dot{ } \sigma \tau \iota \varsigma, \pi \lambda o v \rho \alpha \lambda \iota \sigma \tau \iota x \varepsilon \dot{ } \varsigma$

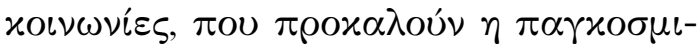

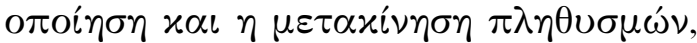

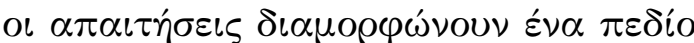

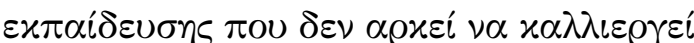

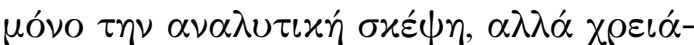

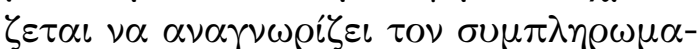

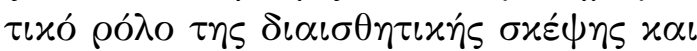

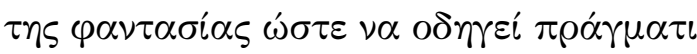

1929, p. 236). This change is made by the student himself and the student who acts individually and collectively in this environment. Nowadays, as the frontiers of technology, economy and communication are not distinct or are lacking, the challenges of Education for Change are more intense and stress the relationship of action and change, but also of school and society (Council of Europe, 2014 ). This action for change is a fundamental goal of R.E. Change is a learning and teaching process, but it is also a goal, too. Basically, the transformation of knowledge into new knowledge is the foundation of this pedagogical approach to religious knowledge. It is a process of changing what one knows in the light of the new knowledge offered in the classroom. This equates to drastic change if he/she had no prior knowledge, change if he/she knew something that was wrong and a partial change if he/she did not know it very well. The process itself involves action. As has already been studied, thinking and reflection are basic learning processes in conceptualizing reality, but in themselves they do not lead to knowledge. The action associated with them gives value to analyzing an issue and solving a problem. In the era of rapid changes in pluralist societies, caused by globalization and the movement of populations, requirements form a field of education that is not enough to only cultivate analytical thinking, but needs to recognize the complementary role of intuitive thinking and imagination so that it actually leads to transformation (de Souza, 2008). R.E. is formed on the basis of this learning approach. It is the combination of thinking, reflection and action that involves the process of change and transformation. We essentially focus on a learning that includes theoretically 
$\sigma \tau o \nu \mu \varepsilon \tau \alpha \sigma \chi \eta \mu \alpha \tau \imath \sigma \mu o ́$ (de Souza, 2008).

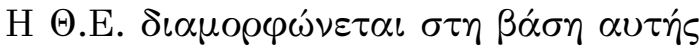

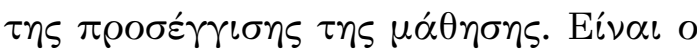
$\sigma u \nu \delta v \alpha \sigma \mu o ́ \varsigma$ $\sigma \tau о \chi \alpha \sigma \mu o u ́, \alpha \nu \alpha \sigma \tau o \chi \alpha \sigma \mu o u ́$

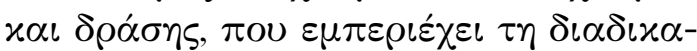

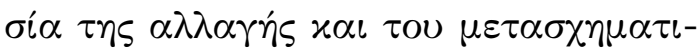

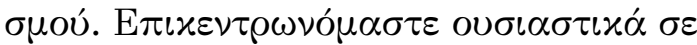

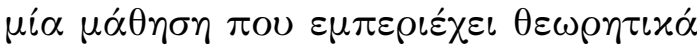

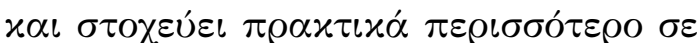

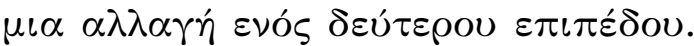

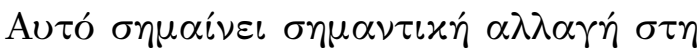
$\sigma x \varepsilon \dot{\psi} \eta x_{\alpha l} \tau \eta \nu \pi \rho \alpha \dot{\xi} \eta \omega \varsigma \alpha \pi 0 \tau \varepsilon \dot{\lambda} \varepsilon \sigma \mu \alpha$

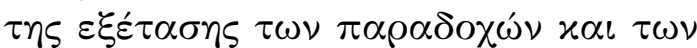

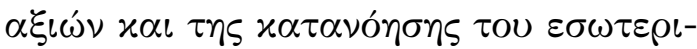

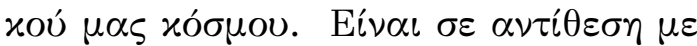

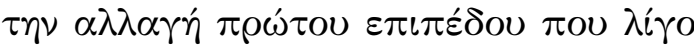

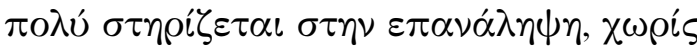
$\sigma u \nu \varepsilon \xi \dot{\varepsilon} \tau \alpha \sigma \eta \dot{\eta} \alpha \lambda \lambda \alpha \gamma \dot{\eta} \tau \omega \nu \pi \alpha \rho \alpha \delta o \chi \omega \dot{\omega} \nu$

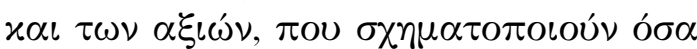

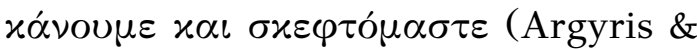
Schon, 1996; Ison \& Russell, 2000).

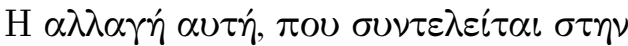

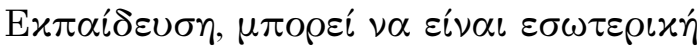

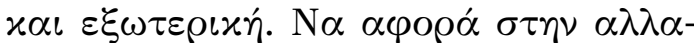

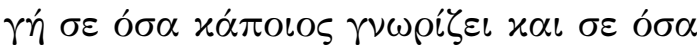

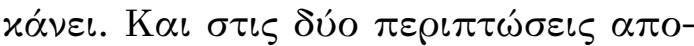

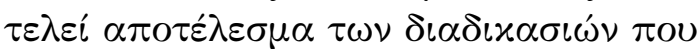

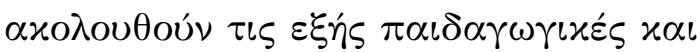
$\delta เ \delta \alpha x \tau \iota x \varepsilon ́ \varsigma \alpha \rho \chi \varepsilon ́ \varsigma:$

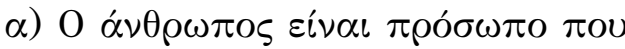
$\alpha \nu \alpha \pi \tau u ́ \sigma \sigma \varepsilon \tau \alpha \iota$ òó $\pi \lambda \varepsilon v \rho \alpha$.

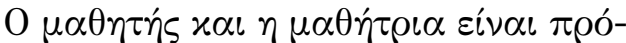

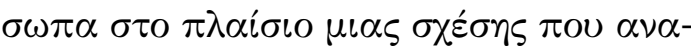

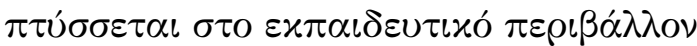

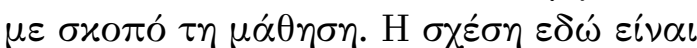

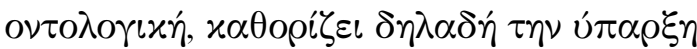

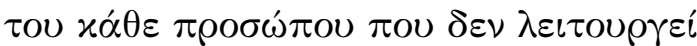

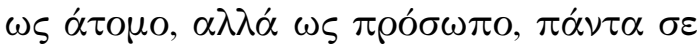

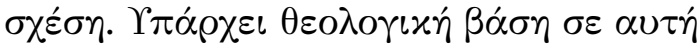

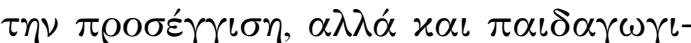
xń (Zizioulas, 1997; Rogers, 1969; 1956; Wubbels, den Brok, vanTartwijk, \& Levy, 2012).

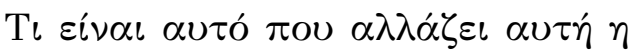

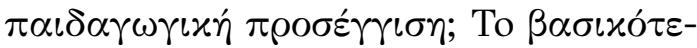

the change and aims in practice to a change of a second level, meaning a significant change in thought and practice as a result of examining the assumptions and values and understanding of our inner world as opposed to change in the first level which is based more or less on repetition, without the conjecture or change of the assumptions and values that shape what we do and think. (Argyris \& Schön, 1996; Ison \& Russell, 2000),

This change, which takes place in Education, may be internal and external; to relate to the change in what one knows and what one does. In both cases it is the result of the following pedagogical and teaching processes:

a) A human being is a person who grows as a whole.

The student is a person in the context of a relationship that develops in the educational environment which has as its aim learning. The relationship here is ontological; i.e. it determines the existence of every person who does not function as an individual, but as a person, always in relation. There is a theological basis to this approach, but also a pedagogical one. (Zizioulas, 1997; Rogers, 1969; 1956; Wubbels, den Brok, van Tartwijk, \& Levy, 2012).

How is this pedagogical approach changing? The most important is the treatment of students. Their teacher knows them in depth and recognizes 


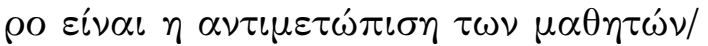

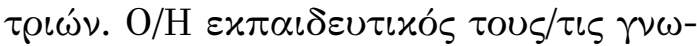

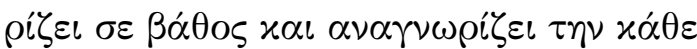

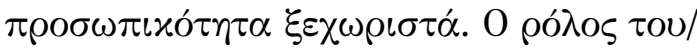

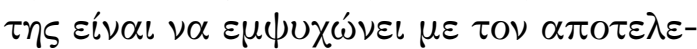

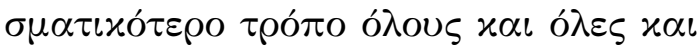

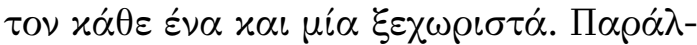

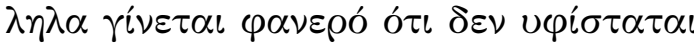

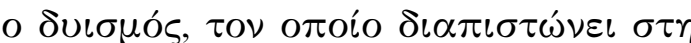

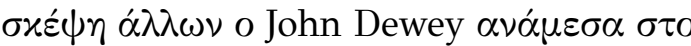

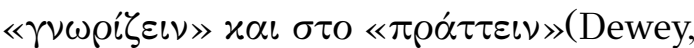
1916). О $\mu \alpha \theta \eta \tau \dot{\eta}^{\prime} / \eta \mu \alpha \theta \dot{\eta} \tau \rho \iota \mu \alpha \theta \alpha i v \varepsilon$

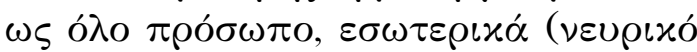

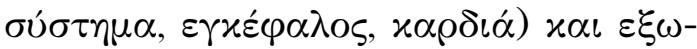

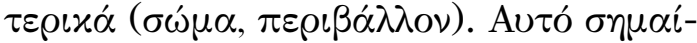
$\nu \varepsilon \iota$ ó $\sigma \iota \tau \eta \nu$ Ex $x \alpha i \delta \varepsilon v \sigma \eta \alpha \nu \alpha \pi \tau u ́ \sigma \sigma \varepsilon \tau \alpha \iota$

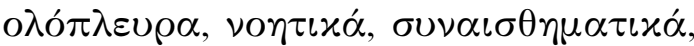

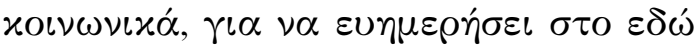
$x \alpha \iota \tau \omega ́ \rho \alpha x^{\prime} \gamma \iota \iota \alpha \pi \dot{\nu} \nu \tau \alpha$.

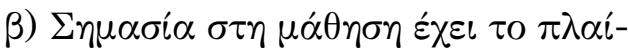

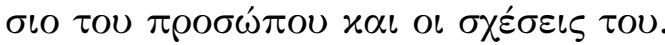

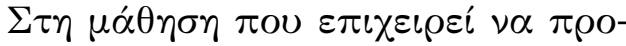

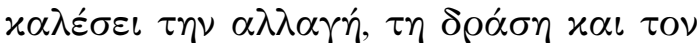

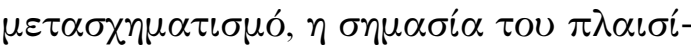

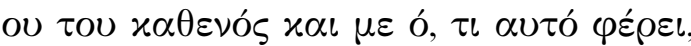

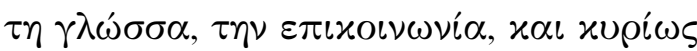

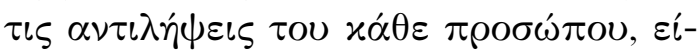

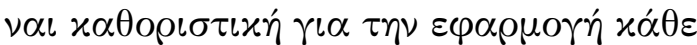

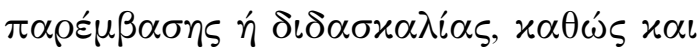

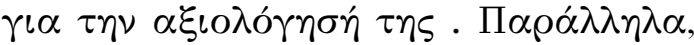

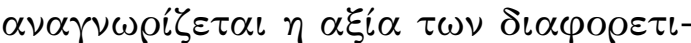

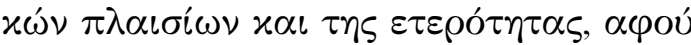

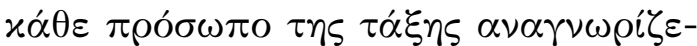

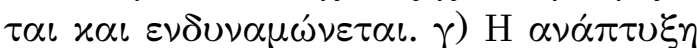

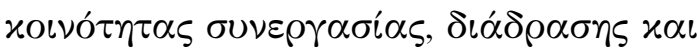
$\alpha \lambda \lambda \eta \lambda \lambda \varepsilon \pi i \delta \rho \alpha \sigma \eta \zeta$.

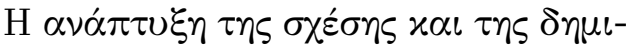

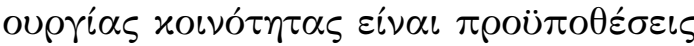

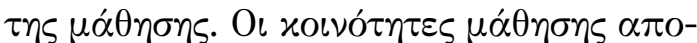

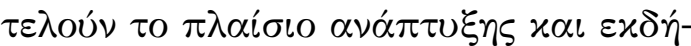

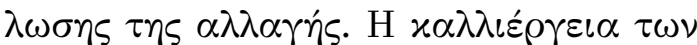

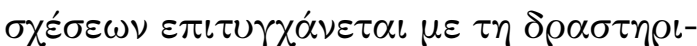

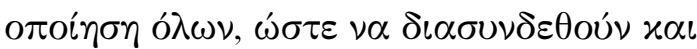

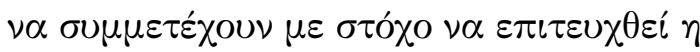

each personality separately. His or her role is to facilitate everyone and each and every one in the most effective way. At the same time, it becomes clear that there is no duality, which John Dewey notes in other thoughts, between knowledge and action (Dewey, 1916). The student learns as a whole person, internally (nervous system, brain, heart) and externally (body, environment). This means that in Education he/she develops all the way, mentally, emotionally, socially, to prosper in here and now and forever.

b) The meaning of learning is to be found in the person's context and his/her relationships.

In learning that attempts to provoke change, action and transformation, the importance of each person's context and what this brings, language, communication and especially the perceptions of each person, is decisive for the implementation of each intervention or teaching, as well as for its evaluation. At the same time, the value of different frames and diversity is recognized, since every person in the class is recognized and empowered.

c) Developing a community of cooperation, participation and interaction.

Developing the relationship and creating a community are prerequisites for learning. Learning communities are the framework for the development and manifestation of change. The cultivation of relationships is achieved by engaging 


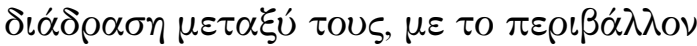

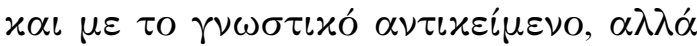

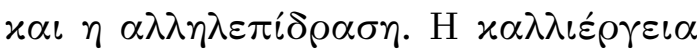

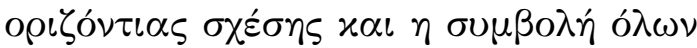

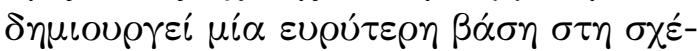

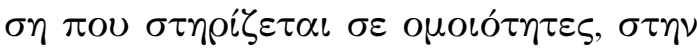

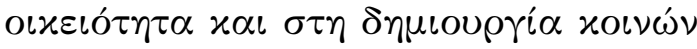

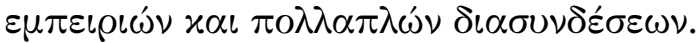

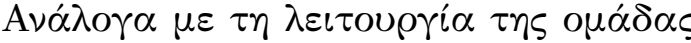

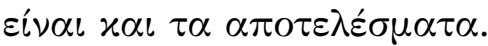

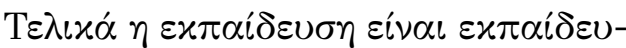

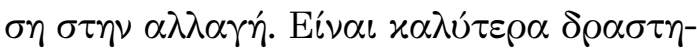

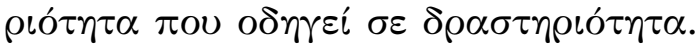

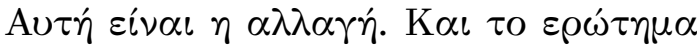

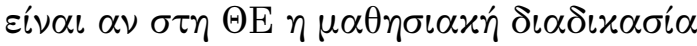

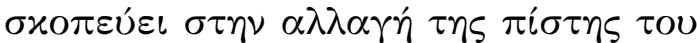

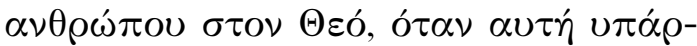

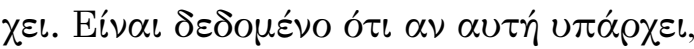

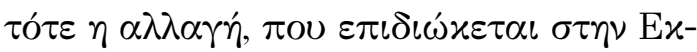

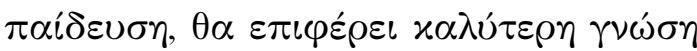

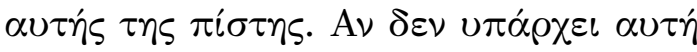

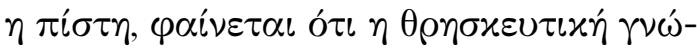

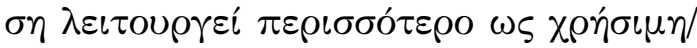
$\omega \varphi \varepsilon \varepsilon \lambda \iota \mu \eta \gamma \nu \omega ́ \sigma \eta \eta$

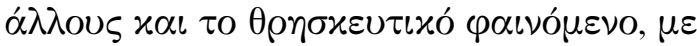

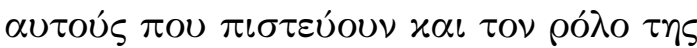
$\theta \rho \eta \sigma x \varepsilon i \alpha \varsigma \sigma \tau \eta \zeta \omega \eta \dot{~} \alpha v \tau \omega^{\prime} \nu \tau \omega \nu \alpha \nu \theta \rho \omega \dot{\pi} \pi \omega \nu$.

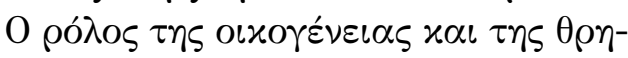

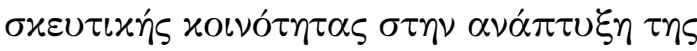

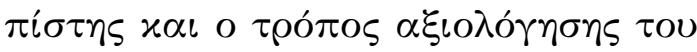

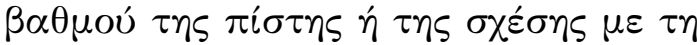

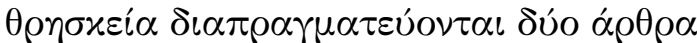

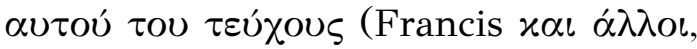

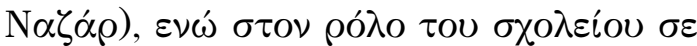

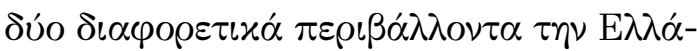

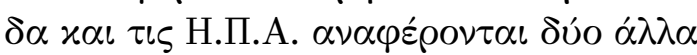

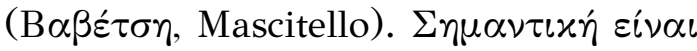

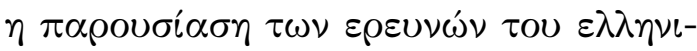

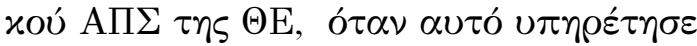

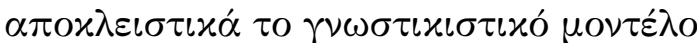

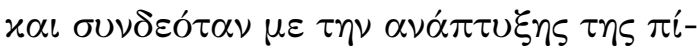

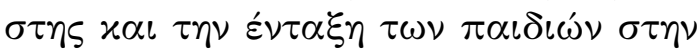

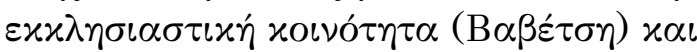

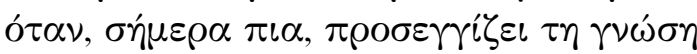

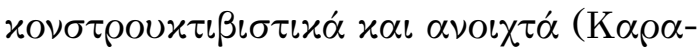

everyone in order to cooperate and participate so that they interact with each other, with the environment and with the subject. The cultivation of a horizontal relationship and the contribution of all, creates a broader basis in the relationship based on similarities, intimacy and the creation of common experiences and multiple interconnections. Results are dependent on the way the group works.

Ultimately, education is education in change. Better an activity that leads to activity. This is the change and leads to the question as to whether in R.E. the learning process aims at a change in human faith in God when it exists. It is assumed that if it exists, then the change sought in Education will bring a better knowledge of this faith. If there is no such faith, it seems that religious knowledge functions more as useful / beneficial knowledge for knowing the others and the religious phenomenon, as well as those who believe and the role of religion in these people's lives.

The role of the family and the religious community in the development of faith and the way of assessing the degree of faith or the relationship with religion are discussed in two articles in this volume (Francis and others, Nazar), while in the role of the school in two different environments, namely Greece and the USA, two others (Vavetsi, Mascitello). It is important to present the researches of the Greek Curriculum when when it served gnosticism exclusively and was associated with the development of faith and the integration of children into the ecclesiastical community (Vavetsi) and when it now approaches knowledge openly and according to constructivism (Karamouzis and others). The influence of 


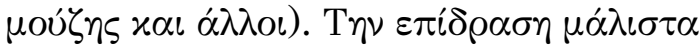

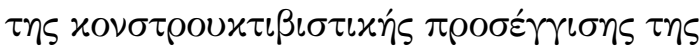

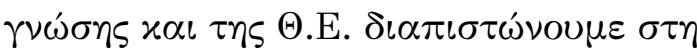

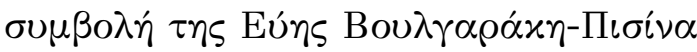

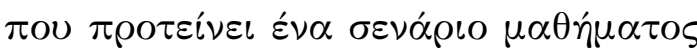

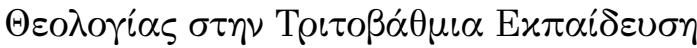

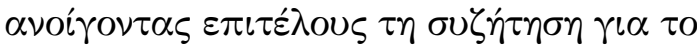

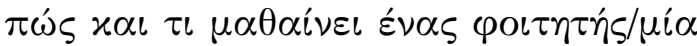

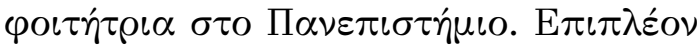

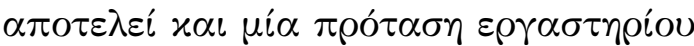
$\delta \iota \alpha \beta i o v \mu \alpha \dot{\theta} \eta \eta \eta \bar{s}$.

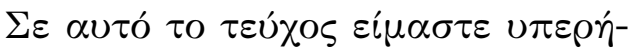

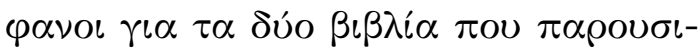

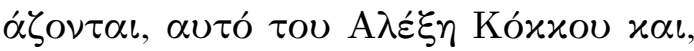

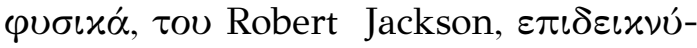

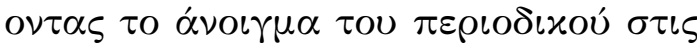

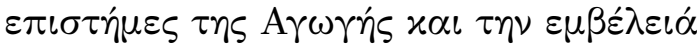

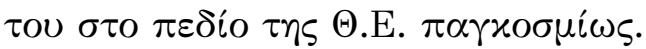

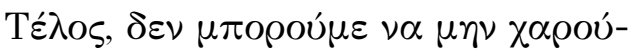

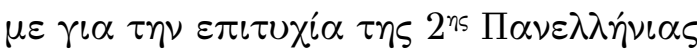

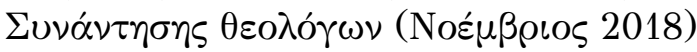

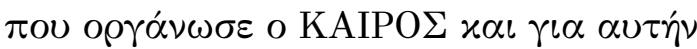

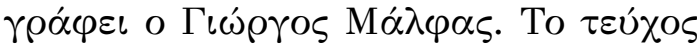

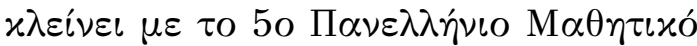

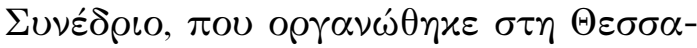

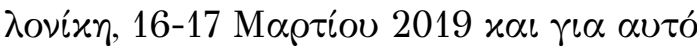

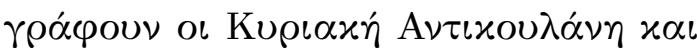

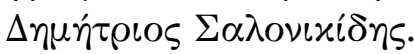

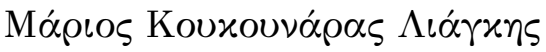

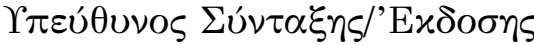

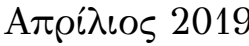

the constructivist approach of knowledge and R.E. is found in the contribution of Evi Voulgaraki-Pisina that proposes a course in Theology in Higher Education, finally opening the debate on how and what a university student learns at University. Moreover the scenario is a fine suggestion for a lifelong learning workshop.

In this issue we are proud to present two books, that of Alexis Kokkos, and of course, the one by Robert Jackson, inaugurating the journal in the science of Education and its scope in the field of R.E. on a worldwide basis.

Finally, we are delighted by the success of the 2nd Panhellenic Theologian Meeting (November 2018) organized by KAIROS on which George Malfas reports. The issue closes with the 5th Panhellenic Student Conference, which was held in Thessaloniki, March 16-17, 2019 and contains reports are by Kyriaki Antikulani and Dimitrios Salonikidis.

\author{
Marios Koukounaras Liagkis \\ Editor-in-Chief \\ April 2019
}

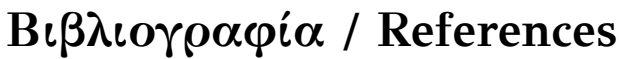

Argyris, C., \& Schön, D. (1996). Organisational Learning II. New York: Addison Wesley.

Council of Europe. (2014). Education for Change. Teacher Manifesto for the 21st Century of the conference "The professional image and ethos of teachers", April 2014, Council of Europe, Strasbourg. Strasbourg: Council of Europe.

de Souza, M. (2008). Education for transformation: meeting students' needs in changing contemporary contexts. International Journal of Children's Spirituality, 13(1), $\sigma \sigma$. 27-37.

Dewey, J. (1938). Experience and Education. In J. Dewey, Later Works, 1935-53, (V. 13, pp. 1-63). Carbondale: Southern Illinois University Press. 
Dewey, J. (1929). Experience and Nature. London: George Allen and Unwin Ltd.

Dewey, J. (1916). Democracy and Education. New York: The Macmillan Company.

Ison, R., \& Russell, D. (2000). Agricultural Extension and Rural Development: breaking out of traditions, a second-order systems perspective. Cambridge: Cambridge University Press.

Rogers, C. (1956). What it means to become a person. In C. E. Moustakas (Ed.), The Self (pp. 195-211). New York: Harper \& Bros.

Rogers, C. (1969). Freedom to learn. Colombus Ohio: Charles Merrill Co.

Stenhouse, L. (1975). An Introduction to Curriculum Research and Development. London: Heinemann Educational.

Tindale, S. R., Meisenhelder, H. M., Dykema-Engblade, A. A., \& Hogg, M. A. (2001). Shared cognitions in small groups. In M. A. Hogg, \& S. Tindale (Ed.), Blackwell handbook of social psychology: Group processes (pp.1-30). Oxford, UK: Blackwell.

Vygotsky, L. (1962). Thought and Language. Cambridge, MA: MIT Press

Vygotsky, L. (1978). Mind and Society. Cambridge, MA: Harvard University Press.

Wubbels, T., den Brok, P., van Tartwijk, J., \& Levy, J. (Ed.). (2012). Interpersonal Relationships in Education. An Overview of Contemporary Research. Rotterdam/Boston/Taipei: Sense.

Zizioulas, J. D. (1997). Being as Communion: Studies in Personhood and the Church . Crestwood, N.Y: St Vladimirs Seminary Press. 